\title{
中国2030年前实现碳达峰的路径研究 基于GDP增速的组合分析
}

\author{
刘卫东 ${ }^{1,2^{*}}$, 姜宛贝 ${ }^{1}$, 唐志鹏 ${ }^{1,2}$, 韩梦瑶 $^{1,2}$ \\ 1. 中国科学院地理科学与资源研究所, 中国科学院区域可持续发展分析与模拟重点实验室, 北京 100101 ; \\ 2. 中国科学院大学资源环境学院, 北京 100049 \\ * 通讯作者, E-mail: liuwd@igsnrr.ac.cn
}

收稿日期: 2021-02-25; 收修改稿日期: 2021-12-28; 接受日期: 2022-02-08; 网络版发表日期: 2022-04-14 国家重点研发计划项目(编号: 2016YFA0602804)资助

\begin{abstract}
摘要中国的碳达峰工作已经进入关键时期. 如何在确保 2035 年人均GDP比 2020 年翻一番的大背景下在 2030 年 前实现碳达峰, 并非轻而易举, 而是一个需要进一步研究的重大决策问题. 本文从GDP增速、碳强度下降速率与 碳达峰时间的关系出发, 将“中国碳峰值目标的实现问题”转化为“碳排放强度下降速率的控制问题”. 通过碳强度 关键影响因子识别、碳强度预测模型构建、碳强度及 $\mathrm{CO}_{2}$ 排放量的情景模拟，建立了我国2030年前碳达峰的数 值模拟模型. 研究发现, 实现碳达峰的时间是由碳强度下降速率和GDP增速的相对关系决定的, 而碳强度下降速 率主要取决于能源结构和调控模式. 若“十五五”期间的GDP增速为 $5.0 \%$, 当非化石能源占比为 $23.0 \%$ 及以上时, 中 国能够于 2030 年之前实现碳达峰. 在此达峰情景下, 达峰年份在2025 2029年之间, 峰值平均值为112亿吨, 分布范 围为 105 119 亿吨. 当“十五五”期间 GDP增速为 $4.5 \%$ 、 $5.5 \%$ 和 $6.0 \%$ 时，非化石能源占比分别达到 $23.0 \% 、 25.0 \%$ 和 $27.0 \%$ 时可在任意调控模式下实现达峰目标. 研究结果显示, 中国何时实现碳达峰目标主要取决于能源结构调整 步伐和GDP增速目标.激进的能源转型能够加速实现碳达峰目标, 但可能会增大能源系统的脆弱性.
\end{abstract}

关键词碳排放, 碳达峰, 碳强度, 能源结构, 经济增长速度

\section{1 引言}

为了应对全球气候变化, 中国政府于2015年在“巴 黎气候峰会”上正式承诺二氧化碳排放在2030年左右 达到峰值并争取尽早达峰. 2020年9月，在第七十五届 联合国大会上，习近平主席再次承诺中国将采取更加 有力的政策和措施，争取于 2030 年前达到碳排放峰值,
努力争取 2060 年前实现碳中和。在确保2035年人均 GDP比2020年翻一番的大背景下如何在2030年前实现 碳达峰, 是一个值得深入研究的重要科学问题. 关于这 个问题, 既要考虑碳达峰的需要, 也要考虑经济增长的 需要, 不可偏废任何一方.

此前，已有研究认为中国能否在2030年前实现碳 达峰与经济增速有较大关系(例如，渠慎宁和郭朝先，

\footnotetext{
中文引用格式: 刘卫东，姜宛贝，唐志鹏，韩梦瑶. 2022. 中国2030年前实现碳达峰的路径研究一一基于GDP增速的组合分析. 中国科学：地球科学，52(7): 1268-1282, doi: 10.1360/SSTe-2021-0048

英文引用格式: Liu W, Jiang W, Tang Z, Han M. 2022. Pathways to peak carbon emissions in China by 2030: An analysis in relation to the economic growth rate. Science China Earth Sciences, 65(6): 1057-1072, https://doi.org/10.1007/s11430-021-9901-y
} 
2010; 何建坤, 2013; 柴麒敏和徐华清, 2015), 而经济增 长速度的放缓有利于中国2030年前碳达峰目标的实现 (Tollefson, 2016; Niu等, 2016). 由于中国目前仍是发展 中国家，在相当长的时期里追求适度的中高速增长是 国家富强和实现“中国梦”的必要条件，因而不能寄希 望于大幅降低经济增速来实现2030年碳达峰目标．正 因如此，本文的目的是揭示经济增长速度与碳达峰的 数量关系, 进而模拟基于经济增速的我国碳达峰路径. 为达到以上目的, 本文首先从数学原理上阐述了 GDP 增速与碳强度下降速率的相对关系对碳达峰时间的影 响, 将“中国碳峰值目标的实现问题”转化为“碳排放强 度下降速率的控制问题”; 其次, 通过机器学习方法从 54 个具体的因子指标中识别出不同年份影响碳强度的 关键因子，并在此基础上构建碳强度预测模型；最后， 通过设置2030年情景值和调控模式，基于预测模型刻 画碳强度变化趋势，并结合不同的GDP增长速度模拟 不同情景下中国 $\mathrm{CO}_{2}$ 排放量的变化轨迹, 从而得出各 种碳达峰路径.

\section{2 碳排放达峰研究综述}

在碳排放达峰研究领域，国内外学者通常通过构 建预测模型和设置情景来模拟分析不同情景下中国实 现碳峰值目标的时间和峰值水平(表1). 常见的碳达峰 预测模型包括Kaya恒等式(Yuan等，2014)、IPAT模型 (杜强等，2012)、STIRPAT模型(王凯等，2017)、GM $(1,1)$ 模型(Liu等，2014)、协整方程(冯宗宪和王安静, 2016)、面板回归(Pao和Tsai，2010)、环境库兹涅茨 EKC曲线(吴立军和田启波，2016)、能源系统模型 (Zhou等，2013)、投入产出模型(Su等，2021)、LEAP 模型(Lin等, 2018)、CGE模型(王勇等, 2017)等.

情景设置是情景分析的基本前提，不同的情景设 置意味着对碳排放影响因素的发展趋势的预期不同. 以往研究表明经济增长、能源消耗、能源结构、产业 结构、技术进步为影响碳达峰主要因素, 因而国内外 学者通常围绕以上变量进行碳排放达峰的情景设置 (姜克隽等, 2016). 例如, 王勇和王颖(2019)参考美国能 源信息署(EIA)《能源展望(2017)》将中国未来经济发 展设置高速、基准、低速三种 G D P 增速情景, 2017 2030年GDP年均增速分别为 $5.3 \% 、 4.9 \%$ 、 4.6\%. 莫建雷等(2018)设定基准情景下2020 2030年能
源消费的增长速率为2 3\%. Wang和Zhang(2017)、Xu 等(2020)、Su等(2021)将2030年非化石能源的比重设 置为 $20 \sim 23 \%$. 其中Wang 和Zhang(2017)和Xu等(2020) 根据煤炭、石油、天然气比重的历史变化速率及其未 来需求, 设置不同情景下三者 2030 年的比重分别为 $47.0 \sim 50.0 \% 、 18.0 \sim 19.0 \% 、 10.6 \sim 12.0 \%$. 在产业结构 和技术进步方面， $\mathrm{Li}$ 等(2018)认为中国进入新常态后 经济发展将由投资驱动转变为消费驱动, 判断 2030 年 第三产业比重将上升至60\%。渠慎宁和郭朝先(2010) 假定2009 2050年工业增加值占GDP比重不变, 为 $36.7 \%$. 林伯强和蒋竺均(2009)根据历史变化, 设定 2020 2030年单位工业能耗产生的工业增加值年均增 长率随时间逐渐下降，2020 2030年的年均增长率为 $1.5 \%$. 此外, 亦有学者基于碳税 (马丁和陈文颖, 2016)、碳定价(安祺等，2021)、其他国家碳强度的变 化规律(郭建科, 2015)进行情景设置.

一些学者在对中国经济、能源、技术的历史规律 进行分析以及对未来发展趋势进行判断以后, 认为中 国的碳峰值目标能够较容易实现 (Green和Stern, 2017). 另有学者认为, 在不做出调整、延续过去的能 源、产业政策和技术进步趋势的情况下(BAU情景), 中国不能于 2030 年前实现碳达峰(李惠民和齐晔, 2011; 马丁和陈文颖，2016; Zhang等，2016). Duan等 (2021)通过综合评估模型(IAMs)的多模型比较分析, 认为 “无政策” 情景下可行的碳达峰年份位于 2035 2045年之间. 实现2030年前碳达峰的目标, 中国 需进一步转变经济发展方式, 明确中长期的能源战略 目标、调整产业结构、强化技术进步(付加锋和刘小 敏，2010; Chai和Xu，2014; 林伯强和李江龙，2015; Elzen等, 2016). 此外, 还有学者的研究结果表明, 中国 要于2030年前实现碳达峰, 需要适当放缓经济增长速 度(刘宇等, 2014; Wang等, 2016). 总体而言, 大多数研 究结果表明在基准情景下(既往发展方式)中国不能于 2030年前达峰, 在低碳情景下(转变发展方式)中国有 能力于 2030 年前达到碳峰值.

已有研究从模型方法、情景设置和达峰可能性等 方面为中国碳达峰研究提供了丰富而有意义的数据资 料, 但同时也存在着一些不足. 比如, 大量研究认识到 碳达峰时间与GDP增速具有紧密关系(渠慎宁和郭朝 先, 2010; Niu等, 2016; 王勇和王颖, 2019), 但如何建立 GDP增速与碳达峰时间的数量关系缺少研究. 在情景 
表 1 部分中国碳达峰研究

\begin{tabular}{|c|c|c|c|c|}
\hline 作者, 发表年 & 方法 & 达峰年份 & 碳峰值预测值(亿吨) & 情景 \\
\hline \multirow{2}{*}{ Duan等, 2021} & \multirow{2}{*}{ IAMs } & 2035 2045年 & - & 无政策情景 \\
\hline & & 2020年 & - & 全球 $1.5^{\circ} \mathrm{C}$ 温升目标情景 \\
\hline Su等, 2021 & 投入产出优化模型, 情景分析 & 2030年 & 124.1 & - \\
\hline 安祺等, 2021 & 碳定价机制模型, 情景分析 & 2030年 & 106.04 & 碳定价机制情景 \\
\hline \multirow{2}{*}{ Xu等, 2020} & \multirow{2}{*}{ 情景分析, EKC } & 2030年 & 106.9 & 计划能源结构 \\
\hline & & 2025年 & 103.7 & 低碳能源结构 \\
\hline Zhou等, 2019 & 情景分析, LEAP & 2025年 & 95.90 & RFS \\
\hline \multirow{6}{*}{ 王勇和王颖, 2019} & \multirow{6}{*}{$\begin{array}{c}\text { 马尔可夫链, 多目标优化模型, } \\
\text { 情景分析 }\end{array}$} & 2030年 & 116 & GDP高速_能源成本最低情景 \\
\hline & & 2030年 & 113 & GDP中速_能源成本最低情景 \\
\hline & & 2023年 & 109 & GDP中速_政策约束情景 \\
\hline & & 2023年 & 114 & GDP低速_无约束情景 \\
\hline & & 2022年 & 109 & GDP低速_政策约束情景 \\
\hline & & 2024年 & 112 & GDP低速_能源成本最低情景 \\
\hline Li等, 2018 & CGE, ESDM & 2025 2030年 & 96 & “中国梦”情景 \\
\hline \multirow{2}{*}{ 莫建雷等, 2018} & \multirow{2}{*}{ CE3METL, 情景分析 } & 2040年 & - & 基准情景 \\
\hline & & 2030年 & - & 碳定价和非化石能源补贴混合政策情景 \\
\hline Green和Stern, 2017 & Kaya identity & 2020 2025年 & - & - \\
\hline Wang和Zhang, 2017 & 情景分析 & 2020 2030年 & - & 巴黎协定目标情景 \\
\hline Mi等, 2017 & IMEC, 投入产出分析 & 2026年 & 112 & - \\
\hline \multirow{5}{*}{ 顾高翔和王铮, 2017} & \multirow{5}{*}{ CIECIA模型 } & 2030年后 & - & 基准情景 \\
\hline & & 2029年 & 110 & 高耗能部门投资控制情景 \\
\hline & & 2029年 & 略高于 110 & 投资结余投资轻工业、重工业和建筑业 \\
\hline & & 2029年 & 略低于 110 & 投资结余投资商贸零售业服务业 \\
\hline & & 2024年 & 106 & $\begin{array}{c}80 \% \text { 投资结余投资商贸等服务业, 其余作为 } \\
\text { 研发投资以推动技术进步 }\end{array}$ \\
\hline \multirow{3}{*}{ Niu等, 2016} & \multirow{3}{*}{ Kaya identity } & 2032年 & 111.55 & Gm-EIl-Mil \\
\hline & & 2034年 & 117.33 & Gm-EIl-Mim \\
\hline & & 2034年 & 132.05 & Gm-EIm-Mil \\
\hline \multirow{4}{*}{ 马丁和陈文颖, 2016} & \multirow{4}{*}{$\begin{array}{l}\text { 多部门局部均衡模型, } \\
\text { 能源系统优化模型 }\end{array}$} & 2045年 & 140 & 参考情景 \\
\hline & & 2030年 & $100 \sim 108$ & 达峰情景PS1 \\
\hline & & 2030年 & $100 \sim 108$ & 达峰情景PS2 \\
\hline & & 2025年 & $100 \sim 108$ & 达峰情景PS3 \\
\hline 姜克隽等, 2016 & IPAC模型 & 2025年前 & 90 & 全球 $2^{\circ} \mathrm{C}$ 温升目标情景 \\
\hline \multirow{4}{*}{ 柴麒敏和徐华清, 2015} & \multirow{4}{*}{ IAMC 模型 } & 2020年 & 100.5 & 深绿(DGS)情景 \\
\hline & & 2025年 & 105.3 & 浅绿(LGS)情景 \\
\hline & & 2030年 & 109.2 & 浅蓝(LBS)情景 \\
\hline & & 2040年 & 119.7 & 深蓝(DBS)情景 \\
\hline 毕超, 2015 & IESOCEM模型 & 2030年 & 93.5 & - \\
\hline \multirow{3}{*}{ 郭建科, 2015} & \multirow{3}{*}{ 指数回归 } & 2027年 & 140 & 基准情景 \\
\hline & & 2021年 & 114 & 英法情景 \\
\hline & & 2033年 & 174 & G7其他国家情景 \\
\hline \multirow{4}{*}{ 渠慎宁和郭朝先, 2010} & \multirow{4}{*}{ STIRPAT, 情景分析 } & 2050年后 & - & 基准情景 \\
\hline & & 2025年 & 73 & 低中模式情景 \\
\hline & & 2028年 & 90 & 中高模式情景 \\
\hline & & 2030 2050年 & $92 \sim 116$ & 其他模式情景 \\
\hline 林伯强和蒋竺均, 2009 & $\mathrm{EKC}$ 曲线 & 2040年后 & - & $\begin{array}{c}\text { 煤炭比重达到 } 60 \% \text { 及以上, GDP增速 } \\
\text { 达到 } 5 \% \text { 及以上 }\end{array}$ \\
\hline
\end{tabular}


设置方面, 既往研究情景设置中的变量多为能源强 度、能源碳强度等刻画性能的综合指标(例如, He, 2014；Su等，2021)，而综合指标对政府制定落地的调 控措施的支撑作用有限, 因而这些研究的理论价值高 于应用价值.

\section{3 方法与数据}

\section{1 理论分析}

$\mathrm{CO}_{2}$ 排放量可以表示为 $\mathrm{GDP}$ 与碳强度(单位国内生 产总值 $\mathrm{CO}_{2}$ 排放量)的乘积, 其表达式为

$$
\mathrm{CE}_{t}=\mathrm{GDP}_{t} \times \mathrm{CED}_{t} \text {, }
$$

式中, $\mathrm{CE}_{t}, \mathrm{GDP}_{t}, \mathrm{CED}_{t}$ 分别为 $t$ 期的 $\mathrm{CO}_{2}$ 排放量, 国内生 产总值和碳排放强度. 考虑上述变量的动态变化, $t+1$ 时期的 $\mathrm{CO}_{2}$ 排放量可表示为

$$
\begin{aligned}
\mathrm{CE}_{t+1} & =\left[\mathrm{GDP}_{t} \times\left(1+R_{\mathrm{GDP}}\right)\right] \times\left[\mathrm{CED}_{t} \times\left(1-R_{\mathrm{CED}}\right)\right] \\
& =\mathrm{GDP}_{t} \times \mathrm{CED}_{t} \times\left[\left(1+R_{\mathrm{GDP}}\right) \times\left(1-R_{\mathrm{CED}}\right)\right],
\end{aligned}
$$

式中, $R_{\mathrm{GDP}}$ 为 $\mathrm{GDP}$ 的增长速率, $R_{\mathrm{CED}}$ 为碳强度的下降速 率. 当 $\left(1+R_{\mathrm{GDP}}\right) \times\left(1-R_{\mathrm{CED}}\right) \leq 1$ 时, $\mathrm{CE}_{t+1} \leq \mathrm{CE}_{t}, \mathrm{CO}_{2}$ 排放量 将不再增长, 即达到峰值. 此时, $R_{\mathrm{CED}} \geq \frac{R_{\mathrm{GDP}}}{1+R_{\mathrm{GDP}}}$. 当 $R_{\mathrm{GDP}}$ 较小, $\frac{1}{1+R_{\mathrm{GDP}}} \approx 1$, 则 $R_{\mathrm{CED}} \geq R_{\mathrm{GDP}}$.

通过这个数学分析, 可发现我国实现碳排放峰值 目标的时间取决于经济增速 $\left(R_{\mathrm{GDP}}\right)$ 与碳排放强度降速 $\left(R_{\mathrm{CED}}\right)$ 的对比关系. 当 $R_{\mathrm{CED}} \geq R_{\mathrm{GDP}}$ 持续发生时, 我国将 达到碳排放峰值; 当 $R_{\mathrm{CED}}$ 接近 $R_{\mathrm{GDP}}$ 时, 也可能出现碳排 放下降的情形. 因此, “中国碳峰值目标的实现问题”可 以转化为“碳排放强度下降速率的控制问题”，即在 GDP增速给定的情况下, 碳达峰时间取决于碳强度下 降速率.

\section{2 解释变量获取}

本文从决策者制定调控措施的视角选取了 54 个具 体的、对碳强度存在潜在影响的因子指标(一级因子), 并将其归纳为化石能源占比、非化石能源占比、高能 耗产业规模及占比、服务业占比、技术水平、居民传 统消费和居民新兴消费7大类别(二级因子). 采用随机 森林算法基于信息熵计算了1980 2019年一级因子及 二级因子的重要性. 根据二级因子重要性的时间变化
趋势选择碳强度的关键驱动因素类别. 再以一级因子 的熵值为权重, 结合一级因子的标准化值, 在二级因 子的框架下加权求和, 得到对应二级因子的数值, 即 本文用于构建预测模型的解释变量. 具体指标及算法 参见刘卫东等(2019)的研究.

\section{3 预测模型构建}

\subsection{1 偏最小二乘回归模型}

本文采用偏最小二乘回归(PLS)算法构建预测模 型. 偏最小二乘回归是在主成分(PCR)方法上的加强与 改进, 在主成分提取的过程中同时考虑自变量(解释变 量)和因变量(被解释变量)的信息, 在多变量的复杂系 统中, PLS利用信息分解的思路, 将自变量系统中的信 息重新组合, 有效提取对系统解释性最强的综合变量, 排除重叠信息或无解释意义信息的干扰，从而克服变 量间多重共线性在系统建模中的不良作用，得到一个 更为可靠的分析结果. 与传统多元线性回归相比, PLS 回归能够在自变量存在严重多重共线性和样本点较少 的情况下进行回归建模, 最终模型中将包含原始的所 有自变量(王惠文, 1999). 本文建立如下偏最小二乘回 归模型:

$\mathrm{CED}_{t}=\beta_{0}+\sum_{k} \beta_{k} X_{k t}+\varepsilon_{t}$,

式中, $\mathrm{CED}_{t}$ 为中国 $t$ 年的碳强度, $X_{k t}$ 为碳强度的解释变 量; $\beta_{k}$ 为相应的回归系数, 反映解释变量对碳强度的边 际贡献; $\beta_{0}$ 为截距, $\varepsilon_{t}$ 指回归残差项.

\subsection{2 模型精度评价}

在获取偏最小二乘回归模型后，利用决定系数 (Coefficient of Determination, $R^{2}$ ) 评价中国碳强度实测 值与模拟值之间的相关性, 利用残差均方根(Root Mean Squared Error, RMSE)表征两者间的一致性. 各 统计量的计算公式如下:

$$
\begin{aligned}
& R^{2}=\frac{\sqrt{\sum(\mathrm{CED}-\overline{\mathrm{CED}})(\overline{\mathrm{CED}}-\overline{\overline{\mathrm{CED}}})}}{\sqrt{\sum(\mathrm{CED}-\overline{\mathrm{CED}})^{2}} \sqrt{\sum(\overline{\mathrm{CED}}-\overline{\overline{\mathrm{CED}}})^{2}}}, \\
& \mathrm{RMSE}=\sqrt{\sum(\mathrm{CED}-\overline{\mathrm{CED}})^{2} / N},
\end{aligned}
$$

式中, $\mathrm{CED}$ 和 $\overline{\mathrm{CED}}$ 分别为中国碳强度实测值及其平均 值; $\overline{\mathrm{CED}}$ 和 $\overline{\overline{\mathrm{CED}}}$ 为模拟碳强度及其平均值, $N$ 为年份数. $R^{2}$ 高于 0.91 表示模型拟合准确, $R^{2}$ 位于 0.82 和 0.90 之间 
表示模型拟合较好, $R^{2}$ 位于 0.66 和 0.81 之间表示模型对 观测值是近似拟合， $R^{2}$ 位于 $0.50 \sim 0.65$ 之间表示变量之 间的关系较弱. RMSE越高表明模型的模拟误差越高 (Farifteh等, 2007).

\section{4 数据来源}

化石能源的燃烧是 $\mathrm{CO}_{2}$ 排放的主要来源，因而已 有的研究一般采用化石能源的消耗量来估算 $\mathrm{CO}_{2}$ 排放 量(刘竹等, 2018). 本文基于煤炭、石油、天然气的消 费量计算中国2006 2019年的 $\mathrm{CO}_{2}$ 排放量，具体估算公 式如下:

$\mathrm{CE}=\sum_{k} \mathrm{AD}_{k} \times \mathrm{FE}_{k}$,

式中, $\mathrm{CE}$ 表示中国化石能源燃烧 $\mathrm{CO}_{2}$ 排放量, $k$ 表示化 石能源类型, $\mathrm{AD}_{k}$ 和 $\mathrm{FE}_{k}$ 分别表示 $k$ 化石能源的消费量 和 $\mathrm{CO}_{2}$ 排放因子. 本文所用到化石能源消费数据来源 于《中国统计年鉴》中“能源消费总量及构成”, $\mathrm{CO}_{2}$ 排放因子来源于《国家温室气体清单》.

本文所用GDP数据来源于《中国统计年鉴》的国 内生产总值. 为了得到不变价GDP, 本文利用“国内生 产总值指数”(上年=100)对GDP进行修正，最终以2005 年不变价进行计量. 碳强度影响因子数据主要来源于 Maddison项目数据库、IEA数据库和《中国能源统计 年鉴》、 《中国工业统计年鉴》和《中国统计年 鉴》. 由于部分碳强度影响因子数据存在缺失, 本文以 《中国统计年鉴》资料为基准，国外的数据资料作为 参考, 对缺失数据进行了插值处理.

\section{4 结果分析}

\section{1 碳强度预测模型构建}

\subsection{1碳强度关键驱动因子识别}

对碳强度影响因子的重要性进行二次项模拟(图 1), 可以看到, 非化石能源占比、服务业占比、居民新 兴消费的重要性整体呈现出上升的趋势，其信息熵值 分别由 $2 \% 、 8 \%$ 和 $0 \%$ 上升至 $14 \% 、 11 \%$ 和 $7 \%$ (图 $1 \mathrm{~b}$, $1 \mathrm{~d} ， 1 \mathrm{~g}$ ); 非化石能源和居民新兴消费重要性的上升幅 度大于服务业占比．技术水平和化石能源占比在 1980 年对碳强度的重要性分别为 $55 \%$ 和 $18 \%$, 其重要性随 时间逐渐下降，2005年后趋于稳定(图1e，1a). 高能耗 产业规模及占比的重要性总体而言有所下降(图1c).
居民传统消费的重要性呈现出先上升后下降的态势 (图1f).

近年来, 我国能源结构向低碳化发展, 能源消费由 以煤炭为主逐渐向清洁能源转变. 产业结构持续优化, 第三产业比重超过第二产业，经济逐步迈入到服务业 主导时代. 各种节能减排技术的科研投入也在不断增 长. 以互联网经济和数字经济为代表的居民新兴消费 普遍性融入居民生活中，居民消费模式逐渐改变. 我 国经济发展方式的转变，使非化石能源消费占比、服 务业占比和居民新兴消费量对碳强度的重要性日益显 现. 高耗能行业规模及占比和居民传统消费作为我国 发展初期经济的增长动力, 其对碳强度的影响相应下 降. 作为研究初期碳强度相对重要的两类影响因子, 技术水平和化石能源占比的重要性在经历下降后逐渐 稳定.

\subsection{2 偏最小二乘回归预测模型构建}

根据上述因子对碳强度重要性的变化趋势, 本研 究选择重要性上升和趋于稳定的五类因子, 即化石能 源占比、非化石能源占比、服务业占比、技术水平和 居民新兴消费作为碳强度的关键驱动因子，用于构建 碳强度预测模型. 表2显示了偏最小二乘回归模型的 性能和回归系数. $R^{2}$ 为 0.85 , 表明PLS回归的拟合精度 较高, 碳强度 $85 \%$ 的变异信息被化石能源占比等自变 量解释. 从残差均方根(RMSE)来看, 碳强度的平均模 拟误差为 0.02 千克/元，为实际碳强度平均值的 $8.80 \%$, 表明拟合值与实际值的一致性也较高. 从回归系数来 看, 化石能源占比增加会导致碳强度增长; 非化石能 源占比、服务业占比、技术水平和居民新兴消费增加 则会促进碳强度下降.

\section{2 不同情景下中国碳达峰可能性分析}

\subsection{1 情景设置}

本文的情景设置基于以下因素: (1) 各类指标因子 的历史变化规律; (2) 刘卫东等(2019)基于机器学习开 展的关键因子识别及变化趋势研究结果; (3) 中国碳减 排和能源结构调整目标; (4) 已有研究成果中排放情景 的设定; (5) 与国家应对气候变化战略研究和国际合作 中心、北京理工大学能源与环境政策研究中心、国家 信息中心等合作机构的共同研讨.

2020年12月, 习近平主席在气候雄心峰会上宣布, 

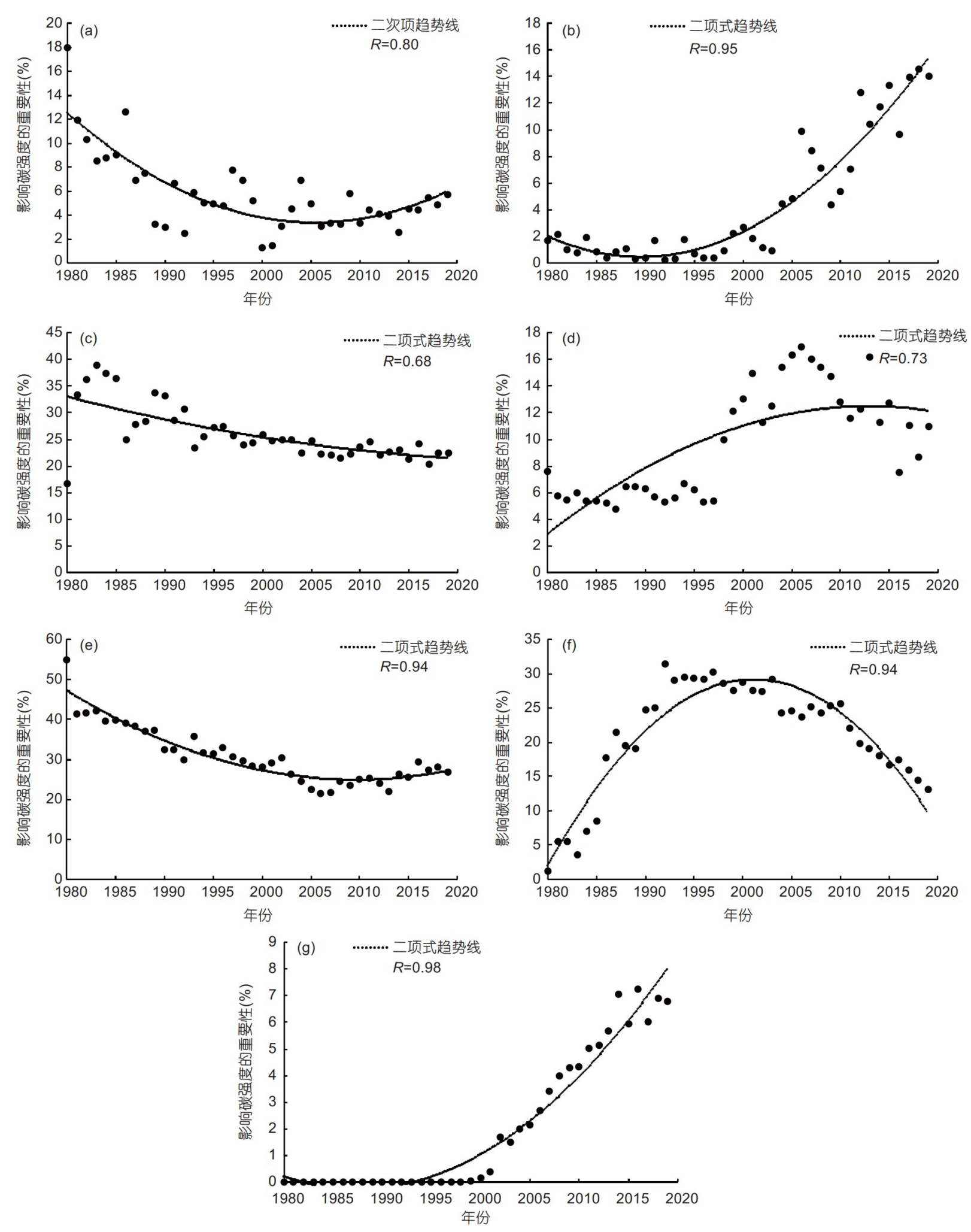

图 1 碳强度影响因子重要性百分比的时间变化趋势

(a) 化石能源占比; (b) 非化石能源占比; (c) 高能耗产业规模及占比; (d) 服务业占比; (e) 技术水平; (f) 居民传统消费; (g) 居民新兴消费 
表 2 偏最小二乘回归模型的性能和回归系数

\begin{tabular}{ccc}
\hline & 参数 & 数值 \\
\hline \multirow{2}{*}{ 性能 } & $R^{2}$ & 0.85 \\
& RMSE & 0.02 \\
\hline \multirow{4}{*}{ 回归系数 } & 截距 & 0.18 \\
& 化石能源占比 & 1.71 \\
& 非化石能源占比 & -0.41 \\
& 服务业占比 & -0.15 \\
& 技术水平 & -0.38 \\
& 居民新兴消费 & -1.27 \\
\hline
\end{tabular}

中国2030年非化石能源占一次能源消费比重将达到 $25 \%$ 左右. 因此, 本文以 $25 \%$ 的非化石能源占比为参照, 设置了 2 个低于、 1 个达到和 1 个高于国家目标的能源 结构情景(ES). 具体来看, $\mathrm{ES}_{1}$ 情景下, 将非化石能源占 比设置为 $20 \%$ ，与 2015 年中国政府在《强化应对气候 变化行动——国国家自主贡献》中的能源结构调整 目标保持一致. $\mathrm{ES}_{2}$ 情景下, 将非化石能源占比设置为 $23 \%$. 该数值高于 $20 \%$ 的原始目标低于 $25 \%$ 的当前目 标. $25 \%$ 的非化石能源占比为 $\mathrm{ES}_{3}$ 情景下的能源结构情 景值, 匹配当前的国家目标. $\mathrm{ES}_{4}$ 情景下, 将非化石能源 占比设置为 $27 \%$. 此外, 降低煤炭消费量通常被认为是 解决中国能源结构问题的关键(刘秉镰等, 2019), 可再 生能源的发展将主要用于弥补煤炭消费的下降(林伯 强和蒋竺均, 2009; Xu等, 2020). 因此, 在本文的情景设 置中, 4 个能源结构情景下可再生能源份额的逐次增加 主要由煤炭份额逐次减少来补充. 根据各类能源比重 的历史规律以及专家对其未来发展趋势的判断，并参 考Wang和Zhang(2017)、Li等(2018)、Xu等(2020)等研 究中对能源结构的情景设定, 设置煤炭、石油、天然 气等化石能源以及水电、风电、太阳能发展、核电等 非化石能源的内部结构(表3).

从发达国家的达峰情况来看, 大多数发达国家是 在借助经济全球化过程完成产业转型升级后才达峰 的. 在此过程中, 这些发达国家将大量中低端制造业转 移到发展中国家，在很大程度上依靠进口高耗能和高 污染产品满足生产及生活需要(刘竹等, 2020), 从而减 少了 $\mathrm{CO}_{2}$ 排放. 因此, 本文考虑产业转移因素, 设置不 转移 $\left(\mathrm{IS}_{1}\right)$ 和转移 $\left(\mathrm{IS}_{2}\right)$ 两种产业结构情景, 以探析产业
转移是否会对中国碳排放达峰造成影响. 从第三产业 比重的历史变化趋势来看, 2011 2015年年均增加0.95 个百分点，2016 2019年年均增加 0.78 个百分点，年均 增长速度随时间略有下降. 2020 2030年按年均增长 0.65 个百分点来看, 2030 年第三产业比重将增至 $61.0 \%$ (2019年第三产业比重为 $53.9 \%$ ). 在产业转移情景下, 既考虑部分制造业会转移至东南亚等国家，又考虑制 造业对于经济发展的重要性，将产业转移情景下 2030 年第三产业比重的情景值设定为 $65 \%$. 假定服务业内 部结构与 2019 年保持一致, 不转移 $\left(\mathrm{IS}_{1}\right)$ 和转移情景下 $\left(\mathrm{IS}_{2}\right) 2030$ 年六类服务业占比的情景值如表3所示.

技术水平和居民新兴消费的情景值主要根据技术 发展和新兴消费的历史趋势和专家组对其未来发展空 间的判断, 以及相关研究的情景设置结果(张露等, 2020; Su等, 2021)进行设定. 另外, 碳强度影响因子的 调控力度设置均速变化 $\left(\mathrm{RC}_{1}\right)$ 和先慢后快 $\left(\mathrm{RC}_{2}\right)$ 两种模 式. $\mathrm{RC}_{1}$ 模式下 2020 2030年因子调控力度逐年匀速变 化. $\mathrm{RC}_{2}$ 模式下, 2020 2025年的变化量为2020 2030年 总变量的 $40 \%, 2025 \sim 2030$ 年为总变量的 $60 \%$. 两种调 控模式下能源结构和产业结构的年变化量如表 4 和表 5 所示. 4 个能源结构情景、 2 个产业结构情景、 2 个调控 力度情景的组合共形成 16 种碳强度情景. 此外, 基于 2035 年人均GDP比 2020 年翻一番的目标和中国GDP的 增长规律，设定“十四五”和“十五五”期间的GDP增速 如表6所列, 以模拟 $\mathrm{CO}_{2}$ 排放量的变化轨迹.

需要说明的是, 由于经济发展、能源结构、产业 结构等各种因素的未来趋势具有不确定性, 本文在有 限空间里并不能穷尽各类指标的所有可能取值. 为了 能够快速模拟预测任何情景下的碳排放轨迹, 本研究 团队研发了“中国碳排放达峰可视化决策支持系统” 1 . 基于该系统, 可以模拟任何情景下的碳达峰路径.

\subsection{2 “十五五”期间GDP增速为 $\mathbf{5 . 0 \%}$ 时的碳达峰 情况}

若调控力度为均速变化, 非化石能源占比为 $20.0 \%$ 时, 在任意一种产业结构情景下, 中国均不能于 2030 年前实现碳排放达峰; 当非化石能源占比为 $23.0 \% 、 25.0 \%$ 和 $27.0 \%$, 所有情景下中国的碳排放量 均能在2030年前达到峰值. 具体而言, $\mathrm{ES}_{1} \mathrm{IS}_{1} \mathrm{RC}_{1}$ 和 $\mathrm{ES}_{1}$

1) 网址见: http://8.131.72.230:8106/, 可通过申请免费使用. 
表 32030 年影响因子的情景设定

\begin{tabular}{|c|c|c|c|c|c|c|c|c|}
\hline \multirow{2}{*}{ 产业 } & \multirow{2}{*}{ 参数 } & \multicolumn{4}{|c|}{ 能源结构(ES) } & \multicolumn{2}{|c|}{ 产业结构(IS) } & \multirow{2}{*}{$\begin{array}{l}\text { 其他 } \\
\text { 因子 }\end{array}$} \\
\hline & & $\mathrm{ES}_{1}$ & $\mathrm{ES}_{2}$ & $\mathrm{ES}_{3}$ & $\mathrm{ES}_{4}$ & $\mathrm{IS}_{1}$ & $\mathrm{IS}_{2}$ & \\
\hline \multirow{3}{*}{$\begin{array}{l}\text { 化石 } \\
\text { 能源 }\end{array}$} & 煤炭比重(\%) & 50.0 & 47.0 & 45.0 & 43.0 & - & - & - \\
\hline & 石油比重(\%) & 20.0 & 20.0 & 20.0 & 20.0 & - & - & - \\
\hline & 天然气比重(\%) & 10.0 & 10.0 & 10.0 & 10.0 & - & - & - \\
\hline \multirow{4}{*}{$\begin{array}{l}\text { 非化 } \\
\text { 石能源 }\end{array}$} & 水电比重 $(\%)$ & 9.0 & 9.0 & 9.0 & 9.0 & - & - & - \\
\hline & 风电比重(\%) & 5.0 & 6.0 & 7.5 & 7.5 & - & - & - \\
\hline & 核能比重(\%) & 2.5 & 2.5 & 3.0 & 3.5 & - & - & - \\
\hline & 太阳能发电比重(\%) & 3.0 & 5.0 & 5.0 & 6.5 & - & - & - \\
\hline \multirow{6}{*}{ 服务业 } & 金融业比重(\%) & - & - & - & - & 8.1 & 8.6 & - \\
\hline & $\begin{array}{c}\text { 信息传输、计算机服务和软件业 } \\
\text { 比重 }(\%)\end{array}$ & - & - & - & - & 3.3 & 3.5 & - \\
\hline & 教育业比重(\%) & - & - & - & - & 3.9 & 4.1 & - \\
\hline & $\begin{array}{c}\text { 卫生和社会保障社会福利比重 } \\
(\%)\end{array}$ & - & - & - & - & 2.4 & 2.5 & - \\
\hline & 文化体育娱乐业比重(\%) & - & - & - & - & 0.8 & 0.9 & - \\
\hline & $\begin{array}{c}\text { 科学研究、技术服务和地质勘查 } \\
\text { 业比重 }(\%)\end{array}$ & - & - & - & - & 2.3 & 2.5 & - \\
\hline \multirow{15}{*}{$\begin{array}{l}\text { 技术 } \\
\text { 水平 }\end{array}$} & 全员劳动生产率(万元/人) & - & - & - & - & - & - & 171694 \\
\hline & $\begin{array}{c}\text { 发电及电站供热加工转换效率 } \\
(\%)\end{array}$ & - & - & - & - & - & - & 47 \\
\hline & 炼焦加工转换效率 $(\%)$ & - & - & - & - & - & - & 92 \\
\hline & 炼油加工转换效率(\%) & - & - & - & - & - & - & 97 \\
\hline & 发电标准煤耗(克/千瓦时) & - & - & - & - & - & - & 290 \\
\hline & 供电标准煤耗(克/千瓦时) & - & - & - & - & - & - & 305 \\
\hline & 发电厂线路损失率(\%) & - & - & - & - & - & - & 6.00 \\
\hline & $\begin{array}{c}\text { 粗钢行业单位综合耗能 } \\
\text { (吨标煤/吨) }\end{array}$ & - & - & - & - & - & - & 0.50 \\
\hline & $\begin{array}{c}\text { 水泥行业单位综合耗能 } \\
\text { (千克标煤/吨) }\end{array}$ & - & - & - & - & - & - & 100 \\
\hline & $\begin{array}{c}\text { 乙烯行业单位综合耗能 } \\
\text { (吨标煤/吨) }\end{array}$ & - & - & - & - & - & - & 0.75 \\
\hline & $\begin{array}{c}\text { 合成氨行业单位综合耗能 } \\
\text { (吨标煤/吨) }\end{array}$ & - & - & - & - & - & - & 1.45 \\
\hline & $\begin{array}{c}\text { 科技拨款占财政总支出的比重 } \\
(\%)\end{array}$ & - & - & - & - & - & - & 5.00 \\
\hline & $\begin{array}{c}\text { 公共建筑单位面积耗能 } \\
\text { (千克标煤/平方米) }\end{array}$ & - & - & - & - & - & - & 15.00 \\
\hline & $\begin{array}{c}\text { 城镇居住建筑单位面积耗能 } \\
\text { (千克标煤/平方米) }\end{array}$ & - & - & - & - & - & - & 7.50 \\
\hline & $\begin{array}{c}\text { 农村居住建筑单位面积耗能 } \\
\text { (千克标煤/平方米) }\end{array}$ & - & - & - & - & - & - & 5.00 \\
\hline \multirow{3}{*}{ 居民新兴消费 } & 互联网宽带接入用户(万户) & - & - & - & - & - & - & 45000 \\
\hline & 高铁营业里程公里数 & - & - & - & - & - & - & 45000 \\
\hline & 电子商务交易额(万亿) & - & - & - & - & - & - & 60 \\
\hline
\end{tabular}


表 4 2020 2030年能源结构调控情景(单位:百分点/年)

\begin{tabular}{|c|c|c|c|c|c|c|c|c|c|}
\hline 调控力度 & 情景 & 时期 & $\begin{array}{l}\text { 煤炭 } \\
\text { (下降) }\end{array}$ & $\begin{array}{l}\text { 石油 } \\
\text { (上升) }\end{array}$ & $\begin{array}{l}\text { 天然气 } \\
\text { (上升) }\end{array}$ & $\begin{array}{l}\text { 水电 } \\
\text { (上升) }\end{array}$ & $\begin{array}{l}\text { 核能 } \\
\text { (上升) }\end{array}$ & $\begin{array}{l}\text { 风电 } \\
\text { (上升) }\end{array}$ & $\begin{array}{l}\text { 太阳能 } \\
\text { (上升) }\end{array}$ \\
\hline \multirow{4}{*}{$\begin{array}{c}\text { 匀速变化 } \\
\left(\mathrm{RC}_{1}\right)\end{array}$} & $\mathrm{ES}_{1}$ & 2020 2030年 & 0.70 & 0.10 & 0.17 & 0.05 & 0.02 & 0.22 & 0.14 \\
\hline & $\mathrm{ES}_{2}$ & 2020 2030年 & 0.97 & 0.10 & 0.17 & 0.05 & 0.02 & 0.31 & 0.32 \\
\hline & $\mathrm{ES}_{3}$ & 2020 2030年 & 1.15 & 0.10 & 0.17 & 0.05 & 0.07 & 0.44 & 0.32 \\
\hline & $\mathrm{ES}_{4}$ & 2020 2030年 & 1.34 & 0.10 & 0.17 & 0.05 & 0.11 & 0.44 & 0.46 \\
\hline \multirow{8}{*}{$\begin{array}{c}\text { 先慢后快 } \\
\left(\mathrm{RC}_{2}\right)\end{array}$} & \multirow{2}{*}{$\mathrm{ES}_{1}$} & 2020 2025年 & 0.51 & 0.07 & 0.13 & 0.04 & 0.02 & 0.16 & 0.10 \\
\hline & & 2026 2030年 & 0.92 & 0.13 & 0.23 & 0.07 & 0.03 & 0.28 & 0.19 \\
\hline & \multirow{2}{*}{$\mathrm{ES}_{2}$} & 2020 2025年 & 0.71 & 0.07 & 0.13 & 0.04 & 0.02 & 0.22 & 0.24 \\
\hline & & 2026 2030年 & 1.28 & 0.13 & 0.23 & 0.07 & 0.03 & 0.40 & 0.43 \\
\hline & \multirow{2}{*}{$\mathrm{ES}_{3}$} & 2020 2025年 & 0.85 & 0.07 & 0.13 & 0.04 & 0.05 & 0.32 & 0.24 \\
\hline & & 2026 2030年 & 1.52 & 0.13 & 0.23 & 0.07 & 0.09 & 0.58 & 0.43 \\
\hline & \multirow{2}{*}{$\mathrm{ES}_{4}$} & 2020 2025年 & 0.98 & 0.07 & 0.13 & 0.04 & 0.08 & 0.32 & 0.34 \\
\hline & & 2026 2030年 & 1.76 & 0.13 & 0.23 & 0.07 & 0.15 & 0.58 & 0.61 \\
\hline
\end{tabular}

表 $52020 \sim 2030$ 年产业结构调整情景(单位:百分点/年)

\begin{tabular}{|c|c|c|c|c|c|c|c|c|}
\hline $\begin{array}{l}\text { 调控力度 } \\
\text { (每年上升) }\end{array}$ & 情景 & 时期 & 金融业 & $\begin{array}{c}\text { 信息传输、 } \\
\text { 计算机服务 } \\
\text { 和软件业 }\end{array}$ & 教育业 & $\begin{array}{l}\text { 卫生和社会保 } \\
\text { 障社会福利 }\end{array}$ & $\begin{array}{c}\text { 文化体育 } \\
\text { 娱乐业 }\end{array}$ & $\begin{array}{l}\text { 科学研究、 } \\
\text { 技术服务等 }\end{array}$ \\
\hline \multirow{2}{*}{$\begin{array}{c}\text { 匀速不变 } \\
\left(\mathrm{RC}_{1}\right)\end{array}$} & $\mathrm{IS}_{1}$ & 2020 2030年 & 0.09 & 0.04 & 0.04 & 0.03 & 0.01 & 0.02 \\
\hline & $\mathrm{IS}_{2}$ & 2020 2030年 & 0.13 & 0.05 & 0.06 & 0.04 & 0.02 & 0.04 \\
\hline \multirow{4}{*}{$\begin{array}{c}\text { 先慢后快 } \\
\left(\mathrm{RC}_{2}\right)\end{array}$} & \multirow{2}{*}{$\mathrm{IS}_{1}$} & 2020 2025年 & 0.06 & 0.03 & 0.03 & 0.02 & 0.00 & 0.02 \\
\hline & & 2026 2030年 & 0.12 & 0.05 & 0.06 & 0.04 & 0.01 & 0.03 \\
\hline & \multirow{2}{*}{$\mathrm{IS}_{2}$} & 2020 2025年 & 0.10 & 0.04 & 0.04 & 0.03 & 0.01 & 0.03 \\
\hline & & 2026 2030年 & 0.18 & 0.07 & 0.08 & 0.05 & 0.02 & 0.06 \\
\hline
\end{tabular}

表 6 2020 2030年GDP增速情景(单位: \%)

\begin{tabular}{cccccccc}
\hline 情景 & 2020 年 & 2021年 & 2022年 & 2023年 & 2024年 & 2025年 & 2026 2030年 \\
\hline 情景0 & 2.0 & 7.0 & 7.0 & 6.0 & 6.0 & 6.0 & 5.0 \\
情景1 & 2.0 & 7.0 & 7.0 & 6.0 & 6.0 & 6.0 & 4.5 \\
情景2 & 2.0 & 7.0 & 7.0 & 6.0 & 6.0 & 6.0 & 5.5 \\
情景3 & 2.0 & 7.0 & 7.0 & 6.0 & 6.0 & 6.0 & 6.0 \\
\hline
\end{tabular}

$\mathrm{IS}_{2} \mathrm{RC}_{1}$ 情景下，2020 2030年中国碳排放量持续增长， 2030 年 $\mathrm{CO}_{2}$ 排放量分别达到118亿吨(图2a)和117亿吨 (图2b). 其他能源的占比不变, 风电比重和太阳能发电 比重分别增加 1 个百分点和 2 个百分点, 非化石能源占 比达到 $23.0 \%$ 时，中国的碳排放量于 2029 年达到峰值, 峰值 $\mathrm{CO}_{2}$ 排放量为 111 亿吨 (情景 $\mathrm{ES}_{2} \mathrm{IS}_{1} \mathrm{RC}_{1}$ ) 和 110 亿吨 (情景 $\mathrm{ES}_{2} \mathrm{IS}_{2} \mathrm{RC}_{1}$ )(图2a, 2b).
在 $\mathrm{ES}_{3} \mathrm{IS}_{1} \mathrm{RC}_{1}$ 和 $\mathrm{ES}_{3} \mathrm{IS}_{2} \mathrm{RC}_{1}$ 情景下, 风电比重和核电 比重在 $\mathrm{ES}_{2}$ 情景的基础上分别增加了 1.5 个和 0.5 个百分 点, 其他能源比重不变, 非化石能源比重提升至 $25.0 \%$. 中国将分别于 2028 年和 2027 年实现碳达峰目标, 碳峰值 约为 108 亿吨(图 $2 \mathrm{a}, 2 \mathrm{~b}$ ). $\mathrm{ES}_{4} \mathrm{IS}_{1} \mathrm{RC}_{1}$ 和 $\mathrm{ES}_{4} \mathrm{IS}_{2} \mathrm{RC}_{1}$ 情景在 $\mathrm{ES}_{3}$ 情景的基础上, 分别增加 1.5 个百分点的太阳能发电 比重和 0.5 个百分点的核电比重，非化石能源比重上升 

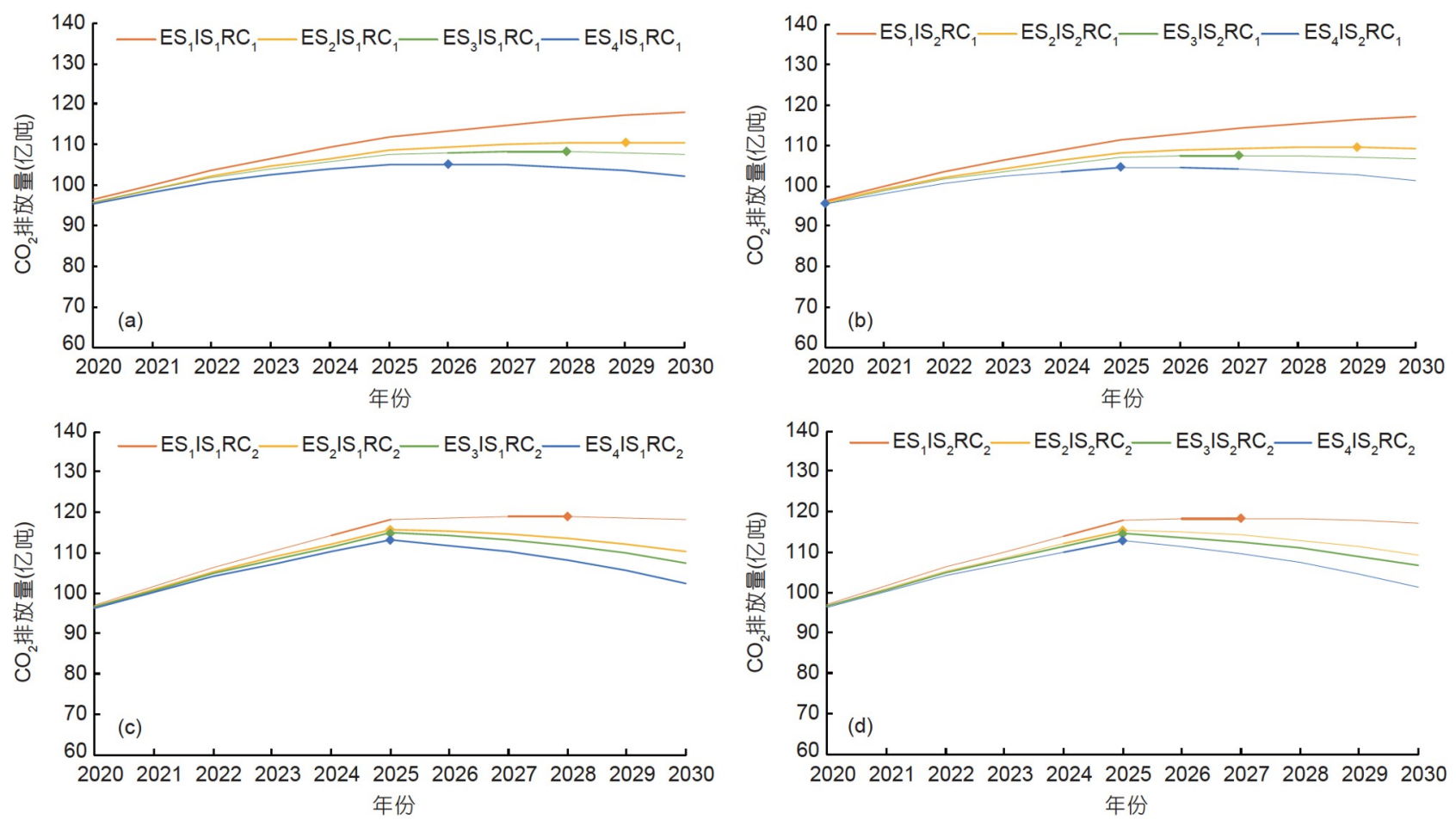

图 $22020 \sim 2030$ 年不同情景下中国 $\mathrm{CO}_{2}$ 排放模拟量

(a) 产业结构 $\mathrm{IS}_{1}$ 和调控力度 $\mathrm{RC}_{1} ;$ (b) 产业结构 $\mathrm{IS}_{2}$ 和调控力度 $\mathrm{RC}_{1}$; (c) 产业结构 $\mathrm{IS}_{1}$ 和调控力度 $\mathrm{RC}_{2} ;$ (d) 产业结构 $\mathrm{IS}_{2}$ 和调控力度 $\mathrm{RC}_{2}$

为 $27.0 \%$. 以上两种情景下, 中国将分别于 2026 年和 2025 年达到碳峰值, 届时 $\mathrm{CO}_{2}$ 排放量均为 105 亿吨(图 $\left.2 a, 2 b\right)$.

若调控力度为先慢后快, 能源结构和产业结构组 合形成的 8 个情景下中国碳排放均能于 2030 年前实现 达峰目标. 当非化石能源占比为 $20.0 \%, \mathrm{ES}_{1} \mathrm{IS}_{1} \mathrm{RC}_{2}$ 和 $\mathrm{ES}_{1} \mathrm{IS}_{2} \mathrm{RC}_{2}$ 情景下中国将分别于 2028 年和 2027 年实现 碳排放达峰, 届时 $\mathrm{CO}_{2}$ 排放量分别达到119亿吨(图2c) 和118亿吨(图2d). 在这种调控方式下, 当非化石能源 占比为 $23.0 \% 、 25.0 \%$ 和 $27.0 \%$, 中国实现碳达峰的年 份均为 2025 年. 达峰时 $\mathrm{CO}_{2}$ 排放量在 $\mathrm{ES}_{2} \mathrm{IS}_{1} \mathrm{RC}_{2}$ 和 $\mathrm{ES}_{2}$ $\mathrm{IS}_{2} \mathrm{RC}_{2}$ 情景下分别为 116 亿吨(图2c)和115亿吨(图2d), $\mathrm{ES}_{3} \mathrm{IS}_{1} \mathrm{RC}_{2}$ 和 $\mathrm{ES}_{3} \mathrm{IS}_{2} \mathrm{RC}_{2}$ 情景下分别为 115 亿吨(图2c)和 115 亿吨(图2d), $\mathrm{ES}_{4} \mathrm{IS}_{1} \mathrm{RC}_{2}$ 和 $\mathrm{ES}_{4} \mathrm{IS}_{2} \mathrm{RC}_{2}$ 情景下分别为 113 亿吨(图2c)和113亿吨(图2d).

\subsection{3 “十五五” 期间GDP增速为 $5.0 \%$ 时碳强度下 降速率与GDP增速的对比}

由第2.1节理论分析可知, 若某一年份的GDP增速 为 $5.0 \%$, 碳强度下降速率超过 $4.76 \%$, 则该年份的 $\mathrm{CO}_{2}$ 排放量相比上一年会有所下降. 由图3可知, 在所有情
景下2020 2030年中国碳强度下降速率不断升高. $\mathrm{ES}_{1}$ $\mathrm{IS}_{1} \mathrm{RC}_{1}$ 和 $\mathrm{ES}_{1} \mathrm{IS}_{2} \mathrm{RC}_{1}$ 情景下, 中国2030年碳强度的下降 速率(分别为 $4.02 \%$ 和 $4.13 \%$ ) 仍低于 $\mathrm{CO}_{2}$ 排放量下降所 需的临界值(4.76\%), 因此在此情景下中国不能于 2030 年前实现碳排放达峰. $\mathrm{ES}_{2} \mathrm{IS}_{1} \mathrm{RC}_{1}$ 和 $\mathrm{ES}_{2} \mathrm{IS}_{2} \mathrm{RC}_{1}$ 情景下, 2030 年中国碳强度的下降速率分别达到 $4.87 \%$ 和 $4.99 \%$, 接近GDP增速(5.0\%)且高于临界值(4.76\%), 因 而此二情景下中国的碳排放量于 2029 年达到峰值.

$\mathrm{ES}_{3} \mathrm{IS}_{1} \mathrm{RC}_{1}$ 和 $\mathrm{ES}_{3} \mathrm{IS}_{2} \mathrm{RC}_{1}$ 情景下, 2029年和 2028 年 碳强度的下降速率分别达到4.94\%和4.82\%(图3), 碳峰 值则分别于 2028 年和 2027 年出现. $\mathrm{ES}_{4} \mathrm{IS}_{1} \mathrm{RC}_{1}$ 和 $\mathrm{ES}_{4} \mathrm{IS}_{2}$ $\mathrm{RC}_{1}$ 情景下, 碳强度下降速率分别于 2027 年和 2026 年 开始接近GDP增速(图3), 且超过临界值(4.76\%), 因此 该情景下的碳峰值于 2026 年和 2025 年出现. 当调控力 度为先慢后快 $\left(\mathrm{RC}_{2}\right)$ 时, $\mathrm{ES}_{1} \mathrm{IS}_{1} \mathrm{RC}_{2}$ 和 $\mathrm{ES}_{1} \mathrm{IS}_{2} \mathrm{RC}_{2}$ 情景下, 碳强度下降速率于 2029 年和 2028 年超过临界值 (4.76\%), 分别达到 $4.97 \%$ 和 $4.85 \%$, 对应的碳峰值年份 则为 2028 和 2027 年. 在其余 6 个情景下, 碳强度下降速 率均在2026年超过或接近GDP增速(图3), 因此上述情 景下中国均在2025年实现碳排放达峰. 

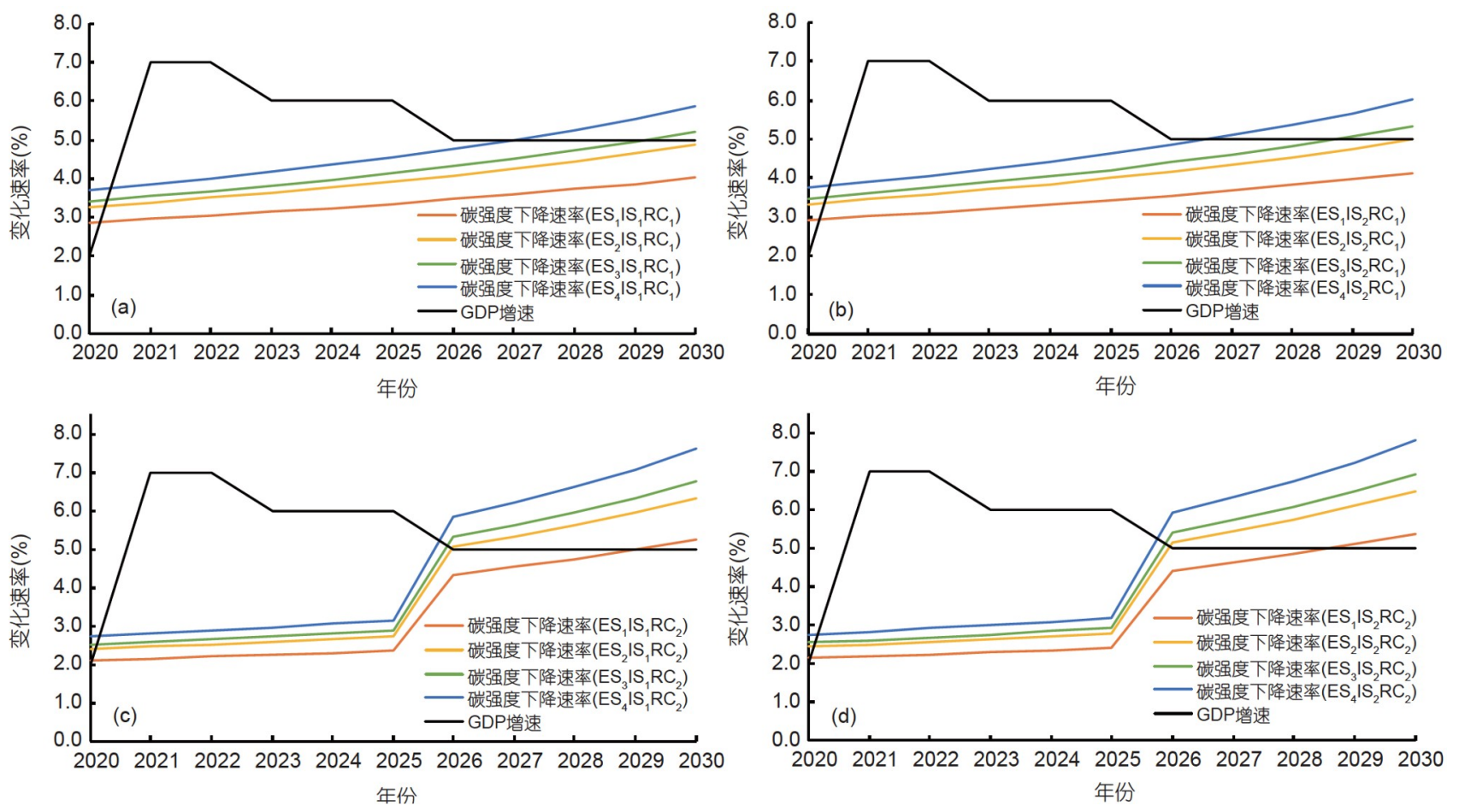

图 $32020 \sim 2030$ 年不同情景下碳强度下降速率与GDP增速对比

(a) 产业结构 $I \mathrm{I}_{1}$ 和调控力度 $\mathrm{RC}_{1} ;$ (b) 产业结构 $\mathrm{IS}_{2}$ 和调控力度 $\mathrm{RC}_{1} ;$ (c) 产业结构 $\mathrm{IS}_{1}$ 和调控力度 $\mathrm{RC}_{2} ;$ (d) 产业结构 $\mathrm{IS}_{2}$ 和调控力度 $\mathrm{RC}_{2}$

\subsection{4 “十五五”期间GDP增速为 $5.0 \%$ 时的碳达峰 不确定性分析}

由于能源结构、产业结构和调控力度情景设定的 差异, 中国碳达峰的年份和峰值水平有所不同. 在本文 考虑的所有情景中，有 $12.50 \%$ 的情景下中国不能于 2030年前实现碳排放达峰(图4a). 对于所有能够达峰 的情景, $\mathrm{CO}_{2}$ 峰值的平均值为 112 亿吨, 最小值为 105 亿 吨， $25 \%$ 四分位为 109 亿吨， $75 \%$ 四分位为 115 亿吨，最 大值为 119 亿吨(图4b). 由此可见达峰情景下的 $\mathrm{CO}_{2}$ 峰 值在105 119亿吨范围内均匀分布(图4b).

从能源结构 $(\mathrm{ES})$ 情景来看, 非化石能源占比为 $20.0 \%$ 时 $\left(\mathrm{ES}_{1}\right)$, 达峰和未达峰的情景比重均为 $50 \%$ $\left(\mathrm{RC}_{2}\right.$ 调控力度下能够达峰)(图 $4 \mathrm{a}$ ). $\mathrm{ES}_{1} \mathrm{IS}_{1} \mathrm{RC}_{2}$ 和 $\mathrm{ES}_{1} \mathrm{IS}_{2}$ $\mathrm{RC}_{2}$ 达峰情景下的峰值水平差距不足 1 亿吨，平均峰值 约为 119 亿吨 (图4b). 非化石能源占比为 $23.0 \%\left(\mathrm{ES}_{2}\right)$ 、 $25.0 \%\left(\mathrm{ES}_{3}\right)$ 和 $27.0 \%\left(\mathrm{ES}_{4}\right)$ 时，相关的所有情景下均能 达峰, 达峰年份最大差距分别为4年、3年和1年(图4a). 峰值范围分别为110 116亿吨、108 115亿吨、 105 113亿吨, 平均值分别为 113 亿吨、 111 亿吨、109
亿吨. 从箱型图来看, $\mathrm{ES}_{2} 、 \mathrm{ES}_{3}$ 和 $\mathrm{ES}_{4}$ 情景下的达峰 $\mathrm{CO}_{2}$ 排放量主要分布于峰值范围两极(图4b). 这主要是 由调控力度模式(RC)的差异所引起.

对于产业结构情景 $\mathrm{IS}_{1}$ 和IS $\mathrm{I}_{2}, 2025$ 年达峰的情景比 例最高，分别为 $37.50 \%$ 和 $50.00 \%$. 2030年前中国不能 实现碳达峰的情景比例分别为 $12.50 \%$ 和 $12.50 \%$ (图4a). 峰值值域范围分别为105 119亿吨和105 118亿吨，分 布均匀, 平均值均为 112 亿吨(图 $4 \mathrm{~b}$ ). 从调控力度(RC) 情景来看, 当调控力度为均速变化 $\left(\mathrm{RC}_{1}\right)$ 时, 有 $25 \%$ 的 情景下不能于2030年前实现碳达峰，2025 2029年实 现碳达峰的情景数基本相同(图4a). $\mathrm{CO}_{2}$ 峰值平均值为 108 亿吨, 最小值为 105 亿吨, 最大值为 111 亿吨, 分布较 为均匀(图4b). 当调控力度为先慢后快 $\left(\mathrm{RC}_{2}\right)$ 时, 所有情 景下均能实现碳达峰, 达峰年份多为2025年(图4a). 峰 值平均值约为 116 亿吨, 范围113 119亿吨, 超过70\%的 峰值集中于113 116亿吨(图4b).

\subsection{5 “十五五” 期间不同GDP增速情景下碳达峰所 需的非化石能源比重}

由上文可知, 相比先慢后快的因子调控模式, 中国 

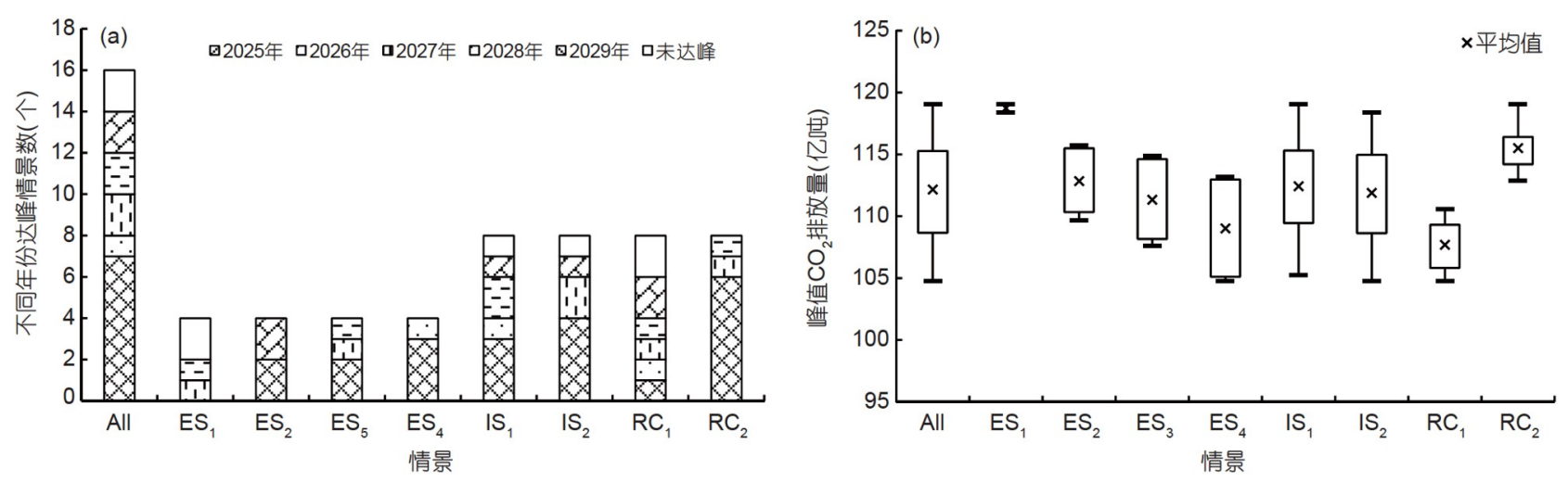

图 4 所有及各能源结构、产业结构、调控力度情景下达峰年份和达峰 $\mathrm{CO}_{2}$ 排放量

(a) 达峰年份情景数; (b) 峰值 $\mathrm{CO}_{2}$ 排放量箱型图及平均值

采用匀速变化的调控模式更难实现碳排放达峰. 而在 匀速变化的调控模式下, 非化石能源的比重为中国能 否于2030年前实现碳峰值目标的关键. 因此，本文测 算了该模式下中国以不同经济增长速度实现碳达峰 2030年所需达到的非化石能源比重，以解析基于经济 增速的中国碳达峰的充分条件(表7)。当“十五五”期间 GDP增速为 $4.5 \%$ 时，中国2030年的非化石能源比重达 到 $23 \%$ 即能实现碳排放达峰. 在产业不转移的情景下, 达峰年份为 2027 年, 峰值为 109 亿吨; 在转移情景下, 达峰年份为 2026 年, 峰值为 108 亿吨. 当GDP增速提高 0.5 个百分点时, $23 \%$ 的非化石能源比重亦可以满足中 国在2030年之前实现碳达峰的目标，不过达峰年份有 所推迟, 峰值水平有所升高. 当GDP增速为 $5.5 \%$ 时, 产 业是否转移会使得碳达峰所需的非化石能源比重出现 差异. 在产业不转移 $\left(\mathrm{IS}_{1}\right)$ 情景下, 2030 年非化石能源的 需求比重为 $27 \%$; 而在产业转移 $\left(\mathrm{IS}_{2}\right)$ ) 情景下, $25 \%$ 的非 化石能源比重即可满足碳达峰需求. 当GDP增速上升 为 $6.0 \%$, 无论何种产业结构情景下，非化石能源比重 均需达到 $27 \%$ 才能使得中国于 2030 年前实现碳达峰目 标. 达峰年份分别为 2029 年( IS $_{1}$ 情景)和 2028 年( IS $_{2}$ 情 景), 达峰 $\mathrm{CO}_{2}$ 排放量分别为 108 亿吨和 107 亿吨.

\section{5 结论及展望}

\section{1 结论}

为了探讨基于 GDP增速的中国碳达峰时间和路 径，本文从GDP增速、碳强度下降速率与碳达峰的关 系出发, 将“中国碳峰值目标的实现问题”转化为“碳排
放强度下降速率的控制问题”, 在碳强度关键影响因子 识别的基础上构建了碳强度预测模型，并在不同情景 下模拟了2020 2030年中国 $\mathrm{CO}_{2}$ 排放量的变化轨迹. 主 要研究结论如下.

(1) 高耗能行业规模及占比和居民传统消费对碳 强度的重要性日益下降，非化石能源消费占比、服务 业占比和居民新兴消费量的重要性不断增长. 技术水 平和化石能源占比为研究初期碳强度较重要的两类影 响因子, 其重要性随时间逐渐下降后趋于稳定.

（2）化石能源占比、非化石能源占比、服务业占 比、技术水平和居民新兴消费作为重要性上升和趋于 稳定的五类因子, 被用于构建碳强度预测模型. 偏最小 二乘(PLS) 预测模型的决定系数 $\left(R^{2}\right)$ 和残差均方根 (RMSE) 分别为 0.85 和 0.02 千克/元，表明PLS预测模型 的拟合精度较高.

（3）碳达峰时间由碳强度下降速率和GDP增速的 相对关系决定, 而碳强度下降速率主要取决于能源结 构和调控模式. 当“十五五”GDP增速为 $5.0 \%$ 时，非化 石能源占比为 $20.0 \%$ 和均速调控情景下 $\left(\mathrm{ES}_{1} \mathrm{IS}_{1} \mathrm{RC}_{1}\right.$ 和 $\left.\mathrm{ES}_{1} \mathrm{IS}_{2} \mathrm{RC}_{1}\right)$, 中国很难于2030年前实现碳峰值; 其他情 景下中国均能于2030年前实现碳排放达峰。达峰情景 下，达峰年份在2025 2029年之间，峰值平均值为 112 亿吨, 分布范围为 $105 \sim 119$ 亿吨.

（4）中国于2030年前实现碳峰值目标的核心在于 能源结构调整步伐与GDP增速目标. 当中国“十五五” 期间的GDP增速为 $4.5 \% 、 5.0 \% 、 5.5 \%$ 和 $6.0 \%$ 时，非化 石能源比重需要分别达到 $23 \% 、 23 \% 、 25 \%$ 和 $27 \%$ 才 能在任意调控模式下于2030年前实现碳排放达峰. 
表 7 “十五五”不同GDP增速情景下碳达峰所需的非化石能源比重(2030年)及对应峰值年份和水平

\begin{tabular}{ccccc}
\hline 情景 & GDP增速(\%) & 非化石能源比重(\%) & 达峰年份 & 峰值(亿吨) \\
\hline & 4.5 & 23 & 2027 年 & 109 \\
产业结构情景 $\mathrm{IS}_{1}$ & 5.0 & 23 & 2029 年 & 111 \\
& 5.5 & 27 & 2027 年 & 106 \\
& 6.0 & 27 & 2029 年 & 108 \\
\hline & 4.5 & 23 & 2026 年 & 108 \\
产业结构情景 $\mathrm{IS}_{2}$ & 5.0 & 23 & 2029 年 & 110 \\
& 5.5 & 25 & 2029 年 & 109 \\
& 6.0 & 27 & 2028 年 & 107 \\
\hline
\end{tabular}

\section{2 讨论}

本文从一个全新的视角提供了基于经济增长速度 的中国碳达峰路径方案. 以往的研究结果表明GDP增 速对碳峰值目标的实现具有重要影响(渠慎宁和郭朝 先, 2010; 何建坤, 2013; 柴麒敏和徐华清, 2015; Niu等, 2016; 王勇和王颖, 2019), 但缺少定量刻画两者关系的 研究. 本文将碳达峰问题分解为碳强度下降速率与 GDP增速的关系，从碳强度影响因素的视角提供了与 GDP增速关联的碳达峰路径，有助于加深对于中国碳 达峰的认识和理解. 另外, 本文设置的情景指标为具 体的、可操作的指标. 既往研究情景设置中的变量多 为能源强度、能源碳强度等综合性指标(例如, $\mathrm{He}$, 2014；Su等，2021)，基于上述指标进行碳达峰分析虽 然能够较好地反映碳达峰对能源结构、技术水平变化 的响应, 但对于决策者制定具体的调控措施而言, 综合 性指标的参考价值相对较小. 本文选取的情景指标直 指调控对象，可以为决策者制定落地的调控措施提供 参考依据.

从国内外学者分析中国碳达峰的研究结果来看 (表1), 本文中得出的峰值水平与以往相关研究大致一 致，但考虑到保持较高GDP增速的需要以及社会经济 发展的现实趋势，本文预测的达峰时间相对较晚. 比 如, Wang和Zhang(2017)的研究结果表明, 在巴黎协定 目标情景下 (2030年非化石能源占比为 $20.0 \%$ ), 中国能 于2020 2030年间实现碳达峰. 但本文的研究结果表 明, 当因子调控力度为均速变化, $20.0 \%$ 的非化石能源 比重不能保证碳峰值于2030年前出现．在Xu等(2020) 的低碳能源结构情景下 $(2030$ 年非化石能源占比为 $23.0 \%)$, 中国碳达峰时间为 2025 年. 而在本文的 $\mathrm{ES}_{2} \mathrm{IS}_{1}$
$\mathrm{RC}_{1}$ 情景和 $\mathrm{ES}_{2} \mathrm{IS}_{2} \mathrm{RC}_{1}$ 情景下 $(2030$ 年非化石能源占比 为 $23.0 \%$ ), 中国碳达峰时间为 2029 年. 此外有研究表 明, 在经济增长速度放缓以及增长内容全面低碳化(低 碳产业结构、建筑、交通、消费等)的发展趋势下，中 国能于2025年前实现碳达峰(姜克隽等，2016; 中国尽 早实现二氧化碳排放峰值的实施路径研究课题组, 2018). 本研究的结果显示, 在保持较高的GDP增速 $(5 \%)$ 以及不考虑产业结构、技术水平以及居民消费的 进一步低碳化调整的前提下，中国实现碳达峰的年份 在2025 2029年之间.

本文的研究结果表明，若中国要于2030年前实现 碳峰值目标，发展非化石能源是关键. 当“十五五”期 间GDP增速为 $5.0 \%$ 时，在均速不变的调控模式中 $\left(\mathrm{RC}_{1}\right)$ ，随着非化石能源比重提高，中国由不能于2030 年前实现碳达峰转变为能够实现，且达峰年份相应提 前, 峰值水平亦逐渐降低. 即便在先慢后快的调控模 式中 $\left(\mathrm{RC}_{2}\right)$ 所有情景都能实现碳达峰，非化石能源占比 的提高仍可以提前达峰年份, 降低峰值水平. 就2030年 前碳达峰目标而言，非化石占比达到 $23.0 \%$ 、23.0\%、 $25.0 \%$ 和 $27.0 \%$ 即能保障在 “十五五”期间 GDP增速为 $4.5 \% 、 5.0 \% 、 5.5 \%$ 和 $6.0 \%$ 时实现该目标. 但从“碳中 和”目标来看，能源加速低碳转型有助于降低峰值水 平, 从而为“碳中和”目标提供有益的基础条件.

因子调控力度先慢后快可加快中国碳达峰步伐, 但是会增加峰值. 比如, 若“十五五”期间GDP的增速为 $5.0 \%$, 当非化石能源占比为 $20.0 \%$ 时，在均速调控的模 式下中国不能实现碳排放达峰，而在先慢后快的模式 下则能实现达峰目标. 该现象的出现仍由碳强度下降 速率与GDP增速的相对关系所引起．在本文先慢后快 的模式中，影响因子2026 2030年的年变化量大于 
2020 2025年, 同样也大于 $\mathrm{RC}_{1}$ 模式中年变化量(表4). 因此， $\mathrm{RC}_{2}$ 模式中2026 2030年碳强度的年下降速率高 于 $\mathrm{RC}_{1}$ 模式中相同时间段的下降速率(图 $3 \mathrm{a}, 3 \mathrm{c}$ ). 如此, 在先慢后快 $\left(\mathrm{RC}_{2}\right)$ 模式下碳强度下降速率在后期更容 易接近或超过GDP增速, 从而实现碳达峰. 因此, 提高 非化石能源比重和改变影响因子的调控模式是实现碳 达峰的可行路径.

\section{3 政策建议}

本文通过模拟不同情景下的 $\mathrm{CO}_{2}$ 排放量发现，能 源结构、调控力度的差异会对中国2030年前碳峰值目 标的实现产生显著影响. 根据本文研究结果提出以下 政策建议.

（1）设立与GDP增速目标相适应的能源结构调整 目标. 本文的研究结果表明若不考虑因子调控模式, 中国于 2030 年前实现碳峰值目标的核心在于能源结构 调整. “十五五” 期间GDP增速为 $4.5 \% 、 5.0 \% 、 5.5 \%$ 和 $6.0 \%$ 时，非化石能源占比分别达到 $23.0 \% 、 23.0 \%$ 、 $25.0 \% 、 27.0 \%$ 即能在任意调控模式下实现上述目标. 因此, 能源结构清洁低碳发展目标需要考虑GDP增速 目标.

(2) 合理选择调控模式. 本文研究表明影响因子变 化先慢后快的调控模式会促使中国 $\mathrm{CO}_{2}$ 排放量达峰的 年份提前, 但同时会增加峰值水平. 因此, 可以合理设 置前后期影响因子调控力度(变化速度)的差距, 在保 证2030年前实现碳达峰的前提下, 尽量降低峰值水平, 以期为 2060 年碳中和目标的实现提供有利条件, 奠定 坚实基础. 比如, 当GDP增速预期为 $5.5 \%$, 非化石能源 比重预期为 $25 \%$ 时, 可设置匀速变化的调控模式; 若 GDP增速预期为 $6.0 \%$, 非化石能源比重预期仍为 $25 \%$ 时, 可设置先慢后快的调控模式, 以保证碳达峰目标 的实现.

(3) 避免过于激进的能源转型. 本文的研究表明, 已承诺的非化石能源比重达到 $25.0 \%$ 的能源结构调整 目标可以保障“十五五”期间 $5.5 \%$ 的GDP增速下于 2030 年前实现碳达峰, 不宜再设置更为激进的能源结构调 整目标. 考虑到未来技术突破的可能性(包括其他非化 石能源技术、碳捕捉和利用技术等), 基于现有技术的 过于激进能源转型可能会导致未来的产能过剩或能源 结构单一化, 从而带来能源风险. 而且, 在可以预见的 未来, 风能和太阳能还难以解决年际波动问题, 其比例
过高会带来能源系统脆弱性的上升.

\section{参考文献}

安祺, 庞军, 冯相昭. 2021. 中国实现碳达峰的政策建议——基于碳 定价机制模型的多情景模拟分析. 环境与可持续发展, 46: 58-70

毕超. 2015. 中国能源 $\mathrm{CO}_{2}$ 排放峰值方案及政策建议. 中国人口. 资源 与环境, 25: 20-27

柴麒敏, 徐华清. 2015. 基于IAMC模型的中国碳排放峰值目标实现 路径研究. 中国人口.资源与环境, 25: 37-46

杜强, 陈乔, 陆宁. 2012. 基于改进IPAT模型的中国未来碳排放预测. 环境科学学报, 32: 2294-2302

冯宗宪, 王安静. 2016. 中国区域碳峰值测度的思考和研究——基于 全国和陕西省数据的分析. 西安交通大学学报(社会科学版), 36: 96-104

付加锋, 刘小敏. 2010. 基于情景分析法的中国低碳经济研究框架与 问题探索. 资源科学, 32: 205-210

郭建科. 2015. G7国家和中国碳排放演变及中国峰值预测. 中外能 源, 20: 1-6

顾高翔, 王铮. 2017. 投资控制下中国产业结构调整的碳治理模拟. 地理研究, 36: 2225-2238

何建坤. 2013. $\mathrm{CO}_{2}$ 排放峰值分析: 中国的减排目标与对策. 中国人 口、资源与环境, 23: 1-9

姜克隽, 贺晨旻, 庄幸, 刘嘉, 高雯, 徐向阳, 陈莎. 2016. 我国能源活 动 $\mathrm{CO}_{2}$ 排放在2020 2022年之间达到峰值情景和可行性研究. 气 候变化研究进展, 12: 167-171

李惠民, 齐晔. 2011. 中国2050年碳排放情景比较. 气候变化研究进 展, 7: 271-280

林伯强, 蒋竺均. 2009. 中国二氧化碳的环境库兹涅茨曲线预测及影 响因素分析. 管理世界, (4): 27-36

林伯强, 李江龙. 2015. 环境治理约束下的中国能源结构转变一一基 于煤炭和二氧化碳峰值的分析. 中国社会科学, (9): 84-107

刘秉镰, 陈诗一, 郭庆旺, 林伯强, 张亚斌, 齐鹰飞, 王军, 徐现祥, 蔡 跃洲, 杨新铭, 潘士远, 史宇鹏, 陈冬华, 房宏琳, 李林木, 王伟同, 张学勇, 严成樑. 2019. 增长动力转换与高质量发展. 经济学动态, (6): 63-72

刘卫东, 唐志鹏, 夏炎, 韩梦瑶, 姜宛贝. 2019. 中国碳强度关键影响 因子的机器学习识别及其演进. 地理学报, 74: 2592-2603

刘宇, 蔡松锋, 张其仔. 2014. 2025年、2030年和2040年中国二氧化 碳排放达峰的经济影响——基于动态GTAP-E模型. 管理评论, 26: 3-9

刘竹, 关大博, 魏伟. 2018. 中国二氧化碳排放数据核算. 中国科学: 地球科学, 48: 878-887

刘竹, 孟靖, 邓铸, 路平, 关大博, 张强, 贺克斌, 宫鹏. 2020. 中美贸易 中的隐含碳排放转移研究. 中国科学: 地球科学, 50: 1633-1642

马丁, 陈文颖. 2016. 中国2030年碳排放峰值水平及达峰路径研究. 
中国人口·资源与环境, 26: 1-4

莫建雷, 段宏波, 范英, 汪寿阳. 2018. 《巴黎协定》中我国能源和气 候政策目标: 综合评估与政策选择. 经济研究, 53: 168-181

渠慎宁, 郭朝先. 2010. 基于STIRPAT模型的中国碳排放峰值预测研 究. 中国人口·资源与环境, 20: 10-15

王惠文. 1999. 偏最小二乘回归方法及其应用. 北京: 国防工业出版 社

王凯, 邵海琴, 周婷婷, 刘浩龙. 2017. 基于STIRPAT模型的中国旅游 业碳排放影响因素分析. 环境科学学报, 37: 1185-1192

王勇, 王恩东, 毕芗. 2017. 不同情景下碳排放达峰对中国经济的影 响——基于CGE模型的分析. 资源科学, 39: 1896-1908

王勇, 王颖. 2019. 中国实现碳减排双控目标的可行性及最优路径 ——能源结构优化的视角. 中国环境科学, 39: 4444-4455

吴立军, 田启波. 2016. 中国碳排放的时间趋势和地区差异研究基于工业化过程中碳排放演进规律的视角. 山西财经大学学报, 38: $25-35$

张露, 李永安, 刘学来. 2020. 基于灰色关联分析的民用建筑能耗预 测研究. 建筑技术, 51: 1129-1134

中国尽早实现二氧化碳排放峰值的实施路径研究课题组. 2018. 中 国碳排放: 尽早达峰. 北京: 中国经济出版社

Chai Q M, Xu H Q. 2014. Modeling an emissions peak in China around 2030: Synergies or trade-offs between economy, energy and climate security. Adv Clim Change Res, 5: 169-180

Duan H, Zhou S, Jiang K, Bertram C, Harmsen M, Kriegler E, van Vuuren D P, Wang S, Fujimori S, Tavoni M, Ming X, Keramidas K, Iyer G, Edmonds J. 2021. Assessing China's efforts to pursue the $1.5^{\circ} \mathrm{C}$ warming limit. Science, 372: 378-385

Elzen M, Fekete H, Höhne N, Admiraal A, Forsell N, Hof A F, Olivier J G J, Roelfsema M, van Soest H. 2016. Greenhouse gas emissions from current and enhanced policies of China until 2030: Can emissions peak before 2030? Energy Policy, 89: 224-236

Farifteh J, Van der Meer F, Atzberger C, Carranza E J M. 2007. Quantitative analysis of salt-affected soil reflectance spectra: A comparison of two adaptive methods (PLSR and ANN). Remote Sens Environ, 110: 59-78

Green F, Stern N. 2017. China's changing economy: Implications for its carbon dioxide emissions. Clim Policy, 17: 423-442

He J K. 2014. An analysis of China's $\mathrm{CO}_{2}$ emission peaking target and pathways. Adv Clim Change Res, 5: 155-161

Li J F, Ma Z Y, Zhang Y X, Wen Z C. 2018. Analysis on energy demand and $\mathrm{CO}_{2}$ emissions in China following the Energy Production and Consumption Revolution Strategy and China Dream target. Adv Clim Change Res, 9: 16-26
Lin J, Kang J, Khanna N, Shi L, Zhao X, Liao J. 2018. Scenario analysis of urban GHG peak and mitigation co-benefits: A case study of Xiamen City, China. J Cleaner Production, 171: 972-983

Liu L, Zong H, Zhao E, Chen C, Wang J. 2014. Can China realize its carbon emission reduction goal in 2020: From the perspective of thermal power development. Appl Energy, 124: 199-212

Mi Z, Wei Y M, Wang B, Meng J, Liu Z, Shan Y, Liu J, Guan D. 2017. Socioeconomic impact assessment of China's $\mathrm{CO}_{2}$ emissions peak prior to 2030. J Cleaner Production, 142: 2227-2236

Niu S, Liu Y, Ding Y, Qu W. 2016. China's energy systems transformation and emissions peak. Renew Sustain Energy Rev, 58: $782-795$

Pao H T, Tsai C M. 2010. $\mathrm{CO}_{2}$ emissions, energy consumption and economic growth in BRIC countries. Energy Policy, 38: 7850-7860

Su Y, Liu X, Ji J, Ma X. 2021. Role of economic structural change in the peaking of China's $\mathrm{CO}_{2}$ emissions: An input-output optimization model. Sci Total Environ, 761: 143306

Tollefson J. 2016. China's carbon emissions could peak sooner than forecast. Nature, 531: 425

Wang X, Zhang S. 2017. Exploring linkages among China's 2030 climate targets. Clim Policy, 17: 458-469

Wang Z, Zhu Y, Zhu Y, Shi Y. 2016. Energy structure change and carbon emission trends in China. Energy, 115: 369-377

Xu G, Schwarz P, Yang H. 2020. Adjusting energy consumption structure to achieve China's $\mathrm{CO}_{2}$ emissions peak. Renew Sustain Energy Rev, 122: 109737

Yuan J, Xu Y, Hu Z, Zhao C, Xiong M, Guo J. 2014. Peak energy consumption and $\mathrm{CO}_{2}$ emissions in China. Energy Policy, 68: 508523

Zhang X, Karplus V J, Qi T, Zhang D, He J. 2016. Carbon emissions in China: How far can new efforts bend the curve? Energy Economics, 54: $388-395$

Zhou N, Fridley D, Khanna N Z, Ke J, McNeil M, Levine M. 2013. China's energy and emissions outlook to 2050: Perspectives from bottom-up energy end-use model. Energy Policy, 53: 51-62

Zhou N, Price L, Yande D, Creyts J, Khanna N, Fridley D, Lu H, Feng W, Liu X, Hasanbeigi A, Tian Z, Yang H, Bai Q, Zhu Y, Xiong H, Zhang J, Chrisman K, Agenbroad J, Ke Y, McIntosh R, Mullaney D, Stranger C, Wanless E, Wetzel D, Yee C, Franconi E. 2019. A roadmap for China to peak carbon dioxide emissions and achieve a $20 \%$ share of non-fossil fuels in primary energy by 2030. Appl Energy, 239: 793-819

(责任编委: 朴世龙) 